\title{
Perioperative outcomes of coronary artery bypass graft surgery in Johannesburg, South Africa
}

Samantha Reiche ${ }^{1}$, Dineo Mpanya', Katharina Vanderdonck², Shungu Mogaladi², Palesa Motshabi-Chakane ${ }^{3}$ and Nqoba Tsabedze 1* $^{*}$

\begin{abstract}
Background: The perioperative complications in patients with coronary artery disease undergoing coronary artery bypass graft (CABG) surgery have been reported predominantly from developed countries, with a paucity of data from sub-Saharan Africa. We aim to report on the clinical characteristics and perioperative complications in patients with obstructive coronary artery disease, managed with CABG surgery at a tertiary academic hospital in Johannesburg, South Africa.

Methods: We retrospectively reviewed data from adult patients who underwent CABG surgery during a 17-year period (January 2000 - December 2017). Data was collected from the cardiothoracic surgery department's pre- and postoperative reports, the cardiology department's medical records, and anaesthesiology's intra-operative reports. We collected demographic, biochemical, clinical, surgical, echocardiographic, and angiographic data. Outcomes data collected included perioperative complications and mortality.

Results: We analysed 1218 consecutive patient records. The study cohort consisted of 951 (78.1\%) males, and the mean age was $60.1 \pm 10.1$ years. During the study period, 137 (11.2\%) patients demised with cardiac and sepsis-related causes of death accounting for 49.6 and $37.2 \%$, respectively. Other perioperative complications included excessive bleeding in 222 (18.2\%), prolonged ventilation (exceeding $48 \mathrm{~h}$ ) in 139 (11.4\%), and sternal sepsis in 125 (10.3\%). On univariate logistic regression analysis, advanced age, a lower left ventricular ejection fraction, smoking, increased cardiopulmonary bypass (CPB) time, and a higher European System for Cardiac Operative Risk Evaluation (EuroSCORE) II were all significantly associated with mortality. The EuroSCORE II [OR: 0.15 95\%Cl: 0.09-0.22; $p=0.000]$, and prolonged CPB time [OR: $0.01 \mathrm{Cl}$ : 0.00-0.02; $p=0.000$ ] were independent predictors of in-hospital all-cause mortality.

Conclusions: In our study, the crude perioperative mortality rate was $11.2 \%$. Our mortality rate was significantly higher than the mortality rates reported in other developed and developing countries. To better understand the factors driving this high mortality rate, a prospective outcomes registry has been initiated, and this promises to inform on our contemporary mortality and morbidity outcomes.
\end{abstract}

Keywords: Coronary artery disease, Coronary artery bypass graft surgery, Sub-Saharan Africa, Perioperative complications, Mortality

\footnotetext{
* Correspondence: Nqoba.Tsabedze@wits.ac.za

'Division of Cardiology, Department of Internal Medicine, Faculty of Health

Sciences, School of Clinical Medicine, University of the Witwatersrand,

Charlotte Maxeke Johannesburg Academic Hospital, 17 Jubilee Road,

Parktown, Johannesburg 2193, South Africa

Full list of author information is available at the end of the article
}

C C The Author(s). 2021 Open Access This article is licensed under a Creative Commons Attribution 4.0 International License, which permits use, sharing, adaptation, distribution and reproduction in any medium or format, as long as you give appropriate credit to the original author(s) and the source, provide a link to the Creative Commons licence, and indicate if changes were made. The images or other third party material in this article are included in the article's Creative Commons licence, unless indicated otherwise in a credit line to the material. If material is not included in the article's Creative Commons licence and your intended use is not permitted by statutory regulation or exceeds the permitted use, you will need to obtain permission directly from the copyright holder. To view a copy of this licence, visit http://creativecommons.org/licenses/by/4.0/ The Creative Commons Public Domain Dedication waiver (http://creativecommons.org/publicdomain/zero/1.0/) applies to the data made available in this article, unless otherwise stated in a credit line to the data. 


\section{Background}

The prevalence of coronary artery disease (CAD) is rapidly growing in low and middle-income countries (LMIC) [1]. Urbanisation and the adoption of a westernised diet and lifestyle are factors associated with an increased cardiovascular disease risk [2, 3]. Coronary artery bypass graft (CABG) surgery is one of the widely accepted traditional revascularisation strategies for CAD [4]. Despite the increasing number of CABG surgical procedures, there is a lack of data from sub-Saharan Africa reporting on the perioperative outcomes of patients with ischaemic heart disease undergoing CABG surgery [5]. We aim to report on the clinical characteristics and perioperative complications in patients with obstructive coronary artery disease, managed with CABG surgery in a state, academic hospital in Johannesburg, South Africa.

\section{Methods}

We conducted a retrospective review of medical, surgical, and intensive care records of consecutive adult patients aged 18 years and older, with obstructive coronary artery disease who underwent CABG surgery at the Charlotte Maxeke Johannesburg Academic Hospital (CMJAH) between 1 January 2000 and 31 December 2017. Data was collected from the cardiothoracic surgery department's pre- and postoperative reports, the cardiology department's medical records, and anaesthesiology's intra-operative reports. We collected demographic, clinical, biochemical, surgical, echocardiographic, and angiographic data.

Induction of anaesthesia was performed with full monitoring using electrocardiography, pulse oximetry, invasive arterial blood pressure, and central venous pressure monitoring. Opioid-based agents, either fentanyl $0.1 \mathrm{mg} / \mathrm{kg}$ or $2.5 \mu \mathrm{g} / \mathrm{kg}$ sufentanil, with midazolam $0.05 \mathrm{mg} / \mathrm{kg}$ or 0.2 $\mathrm{mg} / \mathrm{kg}$ etomidate were administered. Rocuronium $1 \mathrm{mg} /$ $\mathrm{kg}$ was typically administered for muscle relaxation. After endotracheal intubation, maintenance of anaesthesia was achieved with a volatile anaesthetic (1-2\% sevoflurane end-tidal concentration). During cardiopulmonary bypass, patients received continuous infusions of an opioid (remifentanil/fentanyl/sufentanyl) and propofol. We routinely cooled patients to temperatures between 28 and $32{ }^{\circ} \mathrm{C}$ depending on the complexity of the procedure.

Blood cardioplegia was mixed as four parts of blood for one part of a crystalloid solution (Medsol). The crystalloid solution was initially administered as an induction solution higher in potassium and a maintenance solution with a lower potassium content. In each $500 \mathrm{ml}$ bag of crystalloid solution (induction and maintenance), $35 \mathrm{ml}$ of $50 \%$ glucose and $2 \mathrm{~g}$ of magnesium were added.

Immediately after cross-clamping the aorta, an induction dose of blood cardioplegia was given at $20 \mathrm{ml} / \mathrm{kg}$. An entire induction dose was administered antegrade in some instances, but most surgeons gave $2 / 3 \mathrm{rd}$ of the induction dose antegrade into the aortic root and a third of the dose retrograde into the coronary sinus. The maintenance solution was used at $10 \mathrm{ml} / \mathrm{kg}$ or half of the induction dose for the subsequent doses. The maintenance doses were routinely administered retrograde. Also, as part of the maintenance doses, blood cardioplegia was flushed into each newly anastomosed graft. If the crossclamp time was long, a dose of antegrade blood cardioplegia was repeatedly administered with the maintenance solution. The ischaemic time between doses of cardioplegia did not exceed $20 \mathrm{~min}$.

Postoperatively, all patients were admitted to the cardiothoracic intensive care unit (ICU) until stable enough to be referred to the general cardiothoracic ward. The perioperative period was defined as the total period from admission to discharge post CABG surgery. Data on perioperative outcomes and complications was collected from surgical operative notes, ICU charts, and in-patient files. Variables collected included postoperative haemodynamic status, ventilation requirements, and complications. The European System for Cardiac Operative Risk Evaluation (EuroSCORE) II was calculated using an online calculator [6]. The EuroSCORE II features 18 variables describing patient, cardiac, and cardiac operationrelated factors for predicting the risk of 30-day mortality after cardiac surgery [7]. The Research Electronic Data Capture (REDCap) tool hosted at the University of the Witwatersrand was used as the data collection and management tool.

\section{Statistical analysis}

Continuous variables are summarised as the mean and standard deviation (SD) when normally distributed and as a median and interquartile range (IQR) when the distribution is skewed. We compared normally distributed continuous variables by using the Student t-test. The Wilcoxon rank-sum (Mann-Whitney) test was used to compare medians for non-normal data. Categorical variables are expressed as numbers and percentages. All categorical variables were compared for the study outcome by using the Pearson's chi-square test. Odds ratios (OR) are presented with their $95 \%$ confidence interval (CI). A $p$-value of less than 0.05 was considered statistically significant. Univariable and multivariable logistic regression analyses were performed to assess for predictors of allcause in-hospital mortality. We used STATA MP version 13.1 (StataCorp, Texas) for the statistical analysis.

\section{Results}

A total of 1218 patients were included in the analysis (Fig. 1). During the study period, the total number of CABG surgeries performed per annum varied from year to year, with less than 100 operations performed yearly 


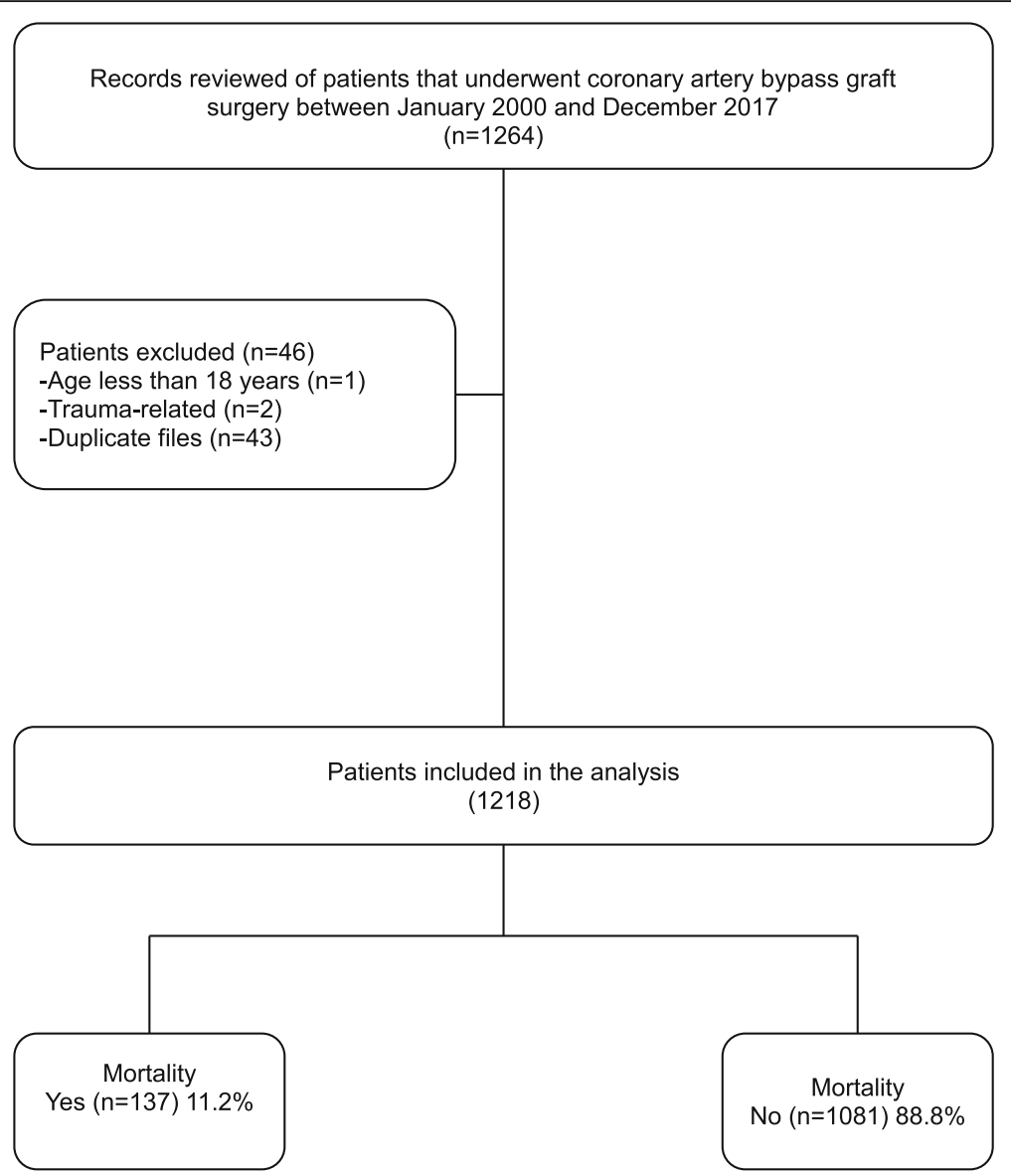

Fig. 1 Study flow chart

on average (Fig. 2). There were 951 (78.1\%) males, and the mean age in the study population was $60.1 \pm 10.1$ years. Hypertension, dyslipidaemia, and diabetes were the most common comorbidities reported in $74.5 \%$, $71.0 \%$, and $32.8 \%$ of patients, respectively. The rest of the perioperative demographic and clinical variables are summarised in Table 1.

The preoperative coronary angiogram demonstrated single, double, and triple vessel disease in 72 (5.9\%), 238 (19.5\%), and 885 (72.7\%) patients, respectively. Left main stem disease was noted in $268(22.0 \%)$ patients, and coronary artery bypass graft surgery was performed as a semi-urgent or elective procedure in $81.0 \%$ of patients. The saphenous vein was grafted in 1074 (88.2\%), the left and right internal mammary artery in $1059(86.9 \%)$ and 82 (6.7\%) patients, respectively. Only $123(10.1 \%)$ patients had grafts other than internal mammary artery grafts. The number of grafts did not differ significantly between the survivors and non-survivors [3 (IQR: $2-4$ ), $p=0.405$ ].

Throughout the study period, crystalloid cardioplegia was administered in only three patients. During the induction of cardiac arrest, the route of blood cardioplegia administration was antegrade in $89.2 \%$, and for maintenance, antegrade infusions were used in $27.6 \%$. In order to augment myocardial perfusion in diastole, the intra-aortic balloon pump was utilised as a cardiac assist device in 424 (37.5\%) patients and was inserted before surgery in 386 (31.7\%) and postoperatively in 51 (4.2\%) patients. The most common indications for insertion of an intra-aortic balloon pump were left ventricular dysfunction (13.8\%), followed by left main stem disease (10.3\%), myocardial infarction (7.8\%), cardiogenic shock (1.1\%), and for catheterisation laboratory related complications in $0.7 \%$.

During the perioperative period, 137 (11.2\%) patients demised. Of these patients, cardiac-related deaths were reported in 68 (49.6\%) patients, 51 (37.2\%) had sepsis, 11 (8.0\%) had pulmonary-related deaths, and six $(4.4 \%)$ had neurological deaths. In some patients, the cause of death involved more than one organ system. The definitive cause of death was not specified in 29 (21.2\%) patients. Eighteen patients required repeat CABG surgery, with half of these patients re-operated within the same admission for CABG surgery (early redo). Among the patients that demised, only 2.2 and $1.5 \%$ were early and late redo cases. Valve replacement and CABG surgery were 


$$
120
$$

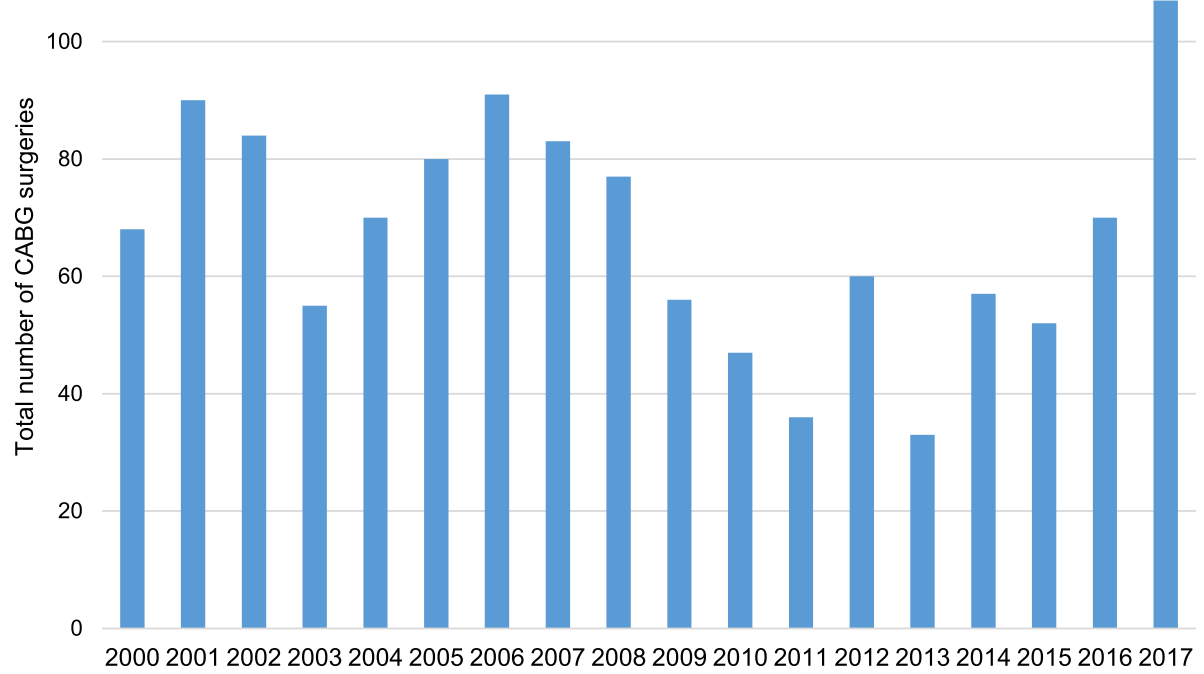

Fig. 2 Number of coronary artery bypass graft surgeries performed between years 2000 and 2017

performed in the same surgical sitting in $85(7.0 \%)$ patients. In these patients, the mortality rate was $27.0 \%$.

Perioperative bleeding requiring a blood transfusion or relook surgery was reported in 222 (18.2\%), of which 109 went back to the operating theatre for haemostasis. However, some of these patients had repeated relooks. Mechanical ventilation exceeding $48 \mathrm{~h}$ was documented in $139(11.4 \%)$ patients, and renal failure was identified as a complication of CABG in $84(6.9 \%)$ patients. The remaining perioperative complications in patients that underwent CABG are summarised in Fig. 3. Relook operations were performed in 256 patients, with some patients sent back to the operating theatre more than once, resulting in a cumulative total of 496 relooks between year 2000 and 2017.

In the entire cohort, $176(14.4 \%)$ patients had sepsis. The median body mass index in patients with and without sepsis was 27.8 (IQR: 24.9-32.4) vs. 27.5 (24.2$30.7) \mathrm{kg} / \mathrm{m}^{2}, p=0.1260$. Among the patients with sepsis, $44.9 \%$ were smokers and $7.4 \%$ had peripheral vascular disease. The most frequent sepsis site was the midline sternotomy incision, reported in 125 (10.3\%) patients. Deep sternal wounds were reported in 16 (1.3\%) and superficial sternal wounds in 36 (2.9\%). The sternal wounds were not characterised in the rest of the patients. Patients with sternal wound infections had a prolonged hospital stay of 23.5 (IQR: 19-37) vs. 13 (IQR: 11-17) days, $p=0.000$, a higher median EuroSCORE II of 2.5 (IQR: $1.1-4.5)$ vs. $1.6(0.9-3.3), p=0.001$ and a longer duration of cardiopulmonary bypass time of 144
(IQR: 118-182) vs. 138 (IQR: 114-166) minutes, $p=$ 0.014 .

Over the 17 years, the all-cause mortality rate ranged between 2.9 and $21.1 \%$, with the highest mortality rate observed in the year 2001 (Fig. 4). When evaluating predictors of in-hospital all-cause mortality, univariable logistic regression analysis showed a linear relationship between mortality and the following variables: advanced age, diabetes mellitus, dyslipidaemia, smoking, New York Heart Association (NYHA) functional class II-IV, a poor left ventricular ejection fraction (LVEF), pre and post intra-aortic balloon pump insertion, a prolonged cardiopulmonary bypass (CPB) time and a high EuroSCORE II. However, a high EuroSCORE II and a prolonged CPB time were the only independent predictors of all-cause mortality in the multivariable logistic regression model (Table 2).

\section{Discussion}

The risk of mortality in patients subjected to CABG surgery depends on the patients' age, comorbidities, physiological functional reserve, degree of left ventricular dysfunction, the surgeons' experience, and the hospital procedure volume [8-10]. The operative all-cause mortality rate in our hospital was $11.2 \%$. Our mortality rate is significantly higher compared to that reported from other developing and developed countries. Data obtained from 1,145,285 patients referred for CABG in the United States of America (USA), from 1989 to 2004, showed a decline in mortality rate from 5.5 to $3.06 \%$, irrespective of the presence of comorbidities [11]. A review of 17,335 
Table 1 Baseline characteristics of patients referred for coronary artery bypass grafting

\begin{tabular}{|c|c|c|c|c|}
\hline & \multirow[t]{2}{*}{ All Patients $(n=1218)$} & \multicolumn{2}{|l|}{ Mortality } & \multirow[b]{2}{*}{$p$-value } \\
\hline & & No $(n=1081)$ & Yes $(n=137)$ & \\
\hline Age, years (SD) & $60.1 \pm 10.1$ & $59.6 \pm 10.1$ & $63.7 \pm 9.7$ & 0.000 \\
\hline Male, n (\%) & $951(78.1)$ & $844(78.1)$ & $107(78.1)$ & 0.994 \\
\hline Ethnicity, n (\%) & & & & 0.344 \\
\hline White & $634(52.0)$ & $569(52.6)$ & $65(47.4)$ & \\
\hline Indian & $358(29.4)$ & $319(29.5)$ & $39(28.5)$ & \\
\hline Black & $137(11.2)$ & $117(10.8)$ & $20(14.6)$ & \\
\hline Mixed ancestry & $79(6.5)$ & $66(6.1)$ & $13(9.5)$ & \\
\hline \multicolumn{5}{|l|}{ Medical history, n (\%) } \\
\hline Hypertension & $908(74.5)$ & $813(75.2)$ & $95(69.3)$ & 0.138 \\
\hline Diabetes mellitus & $400(32.8)$ & $345(31.9)$ & $55(40.1)$ & 0.053 \\
\hline Dyslipidaemia & $865(71.0)$ & $791(73.2)$ & $74(54.0)$ & 0.000 \\
\hline Stroke & $32(2.6)$ & $27(2.5)$ & $5(3.6)$ & 0.427 \\
\hline PVD & $50(4.1)$ & $42(3.9)$ & $8(5.8)$ & 0.277 \\
\hline COPD & 159 (13.0) & $138(12.8)$ & $21(15.3)$ & 0.402 \\
\hline Smoking & $629(51.6)$ & $576(53.3)$ & $53(38.7)$ & 0.001 \\
\hline NYHA class, n (\%) & & & & 0.000 \\
\hline । & $523(48.1)$ & $491(50.7)$ & $32(26.9)$ & \\
\hline$\|$ & $396(36.4)$ & $344(35.5)$ & $52(43.7)$ & \\
\hline III & $141(13.0)$ & $118(12.2)$ & $23(19.3)$ & \\
\hline IV & $27(2.5)$ & $15(1.5)$ & $12(10.1)$ & \\
\hline \multicolumn{5}{|l|}{ Laboratory indices } \\
\hline Haemoglobin, g/dL & $14.4 \pm 1.7$ & $14.5 \pm 1.7$ & $14.2 \pm 1.5$ & 0.107 \\
\hline Sodium, mmol/l & $140 \pm 3.8$ & $140 \pm 3.7$ & $140 \pm 4.8$ & 0.107 \\
\hline eGFR, $\mathrm{ml} / \mathrm{min}$ & $86(71-99)$ & $87(73-101)$ & $74(56-89)$ & 0.000 \\
\hline LVEF, \% & $50.3 \pm 12.8$ & $51.2 \pm 12.2$ & $42.9 \pm 14.8$ & 0.000 \\
\hline CPB time (min) & $139(115-167)$ & $137(114-163)$ & $162(126-211)$ & 0.000 \\
\hline Aortic clamp time (min) & $89(71-107)$ & $89(70-106)$ & $95(72-112)$ & 0.107 \\
\hline EuroSCORE II & $1.6(0.9-3.5)$ & $1.5(0.9-3.1)$ & $5.7(2.5-10.9)$ & 0.000 \\
\hline
\end{tabular}

Data shown as mean \pm standard deviation (SD) and median and interquartile ranges for continuous variables with a normal and skewed distribution, respectively. Categorical variables are summarized as absolute numbers and percentages. COPD Chronic obstructive pulmonary disease; CPB Cardiopulmonary bypass; eGFR Estimated glomerular filtration rate; EuroSCORE European system for cardiac operative risk evaluation; LVEF Left ventricular ejection fraction; NYHA New York Heart Association; PVD Peripheral vascular disease

CABG surgeries performed in Spain between 2013 and 2015 demonstrated a crude mortality rate of 5\% [12]. Similarly, Swart et al. analysed outcomes post CABG in a South African cardio-thoracic private practice and reported a mortality rate of $3 \%[13]$.

Numerous clinical factors may have contributed to a higher mortality rate in our hospital. The patients in our cohort were older than those demonstrated in other studies, with a mean age of 60 years, while the mean age in the group of patients who demised was 63 years. Also, there may be a modest relationship between the surgical experience and the mortality rate. This hypothesis is argued by Peterson et al., who found that the surgeons' experience was a predictor of mortality, independent of hospital volume, and the highest mortality rates were observed when patients were treated at low-volume hospitals by low-experience surgical teams, defined as performing 10 to 85 CABG surgeries per annum $[14,15]$. In our hospital, the number of CABG surgeries was generally under 100 procedures per annum, except for the year 2017, where 107 CABG surgeries were performed. It is worth noting that although fewer CABG surgeries were performed in our hospital, most of our cardiothoracic surgeons are reasonably experienced as they also perform CABG surgeries in private hospitals.

Common postoperative complications associated with CABG reported in the literature are death, myocardial infarction, cardiac arrhythmia, stroke, wound infection, 


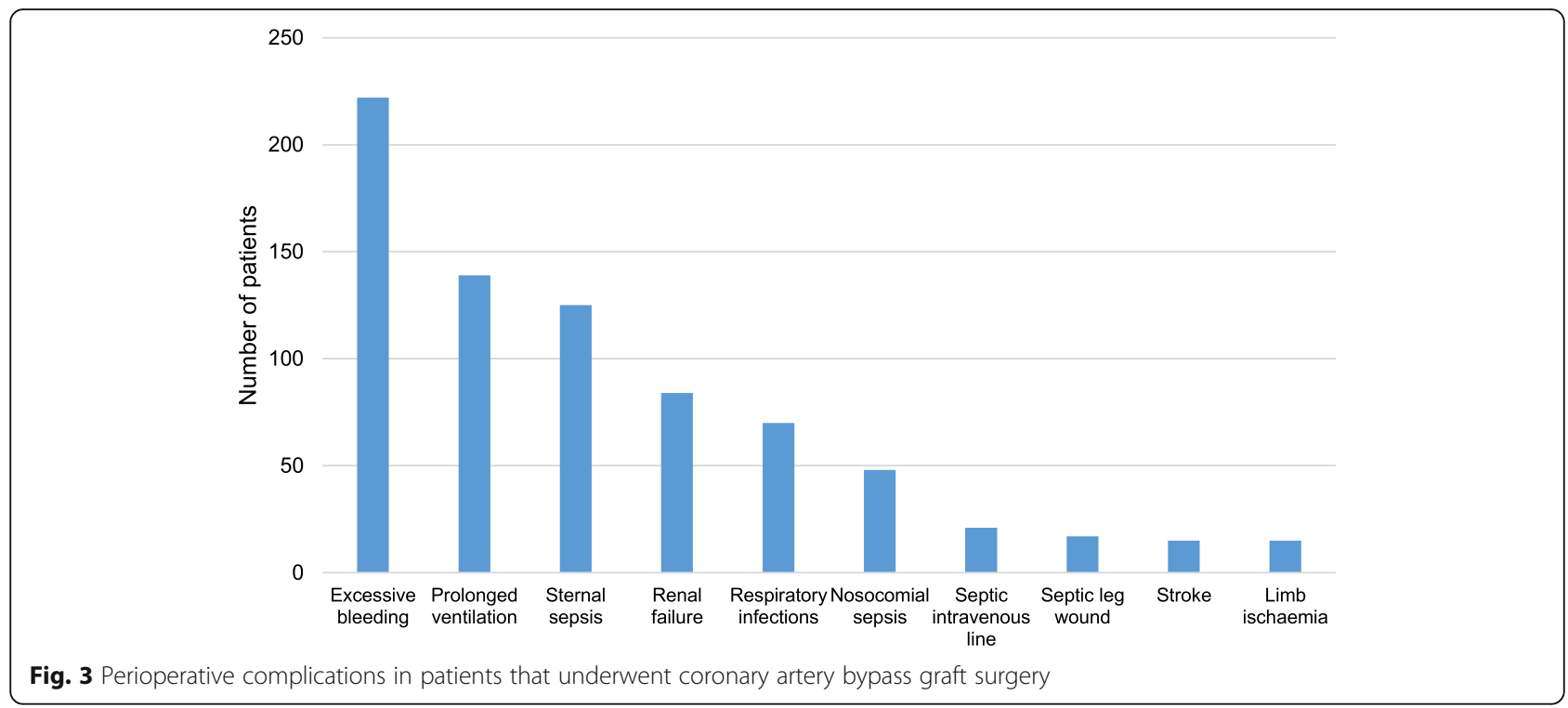

renal dysfunction, and bleeding requiring transfusion or repeat relook surgery [16]. In our study, $11.4 \%$ of patients required ventilation for more than $48 \mathrm{~h}$, and the stroke rate was $1.2 \%$. A similar rate of complications was reported in a study involving 36,588 patients after isolated CABG surgery, where $9 \%$ of patients required prolonged ventilation $(>24 \mathrm{~h})$, and $1.2 \%$ experienced a stroke [17].

In our study, $1.3 \%$ of patients had deep sternal wound infections. This is a relatively high rate when compared to other studies. In larger cohorts, only $0.1 \%$ of patients had deep sternal wound infections [17]. Most data suggest that sepsis development following CABG portends a higher risk of mortality and a longer hospital stay [18-20]. In our cohort, patients with sternal wound infections were hospitalised for approximately 3 weeks.

In contrast, those without sternal wound infections had a median duration of hospitalisation of approximately 2 weeks. Variables associated with an increased risk of developing sepsis after CABG are a raised body mass index (BMI), poor preoperative glycaemic control, smoking, peripheral vascular disease, prolonged duration of cardiac bypass, and repeat or relook surgery [20]. In our study, the CPB time differed significantly between survivors and non-survivors (137 vs. $162 \mathrm{~min}$ ) and independently predicted mortality $(p=0.000)$. Santos et al. studied 1628 patients post CABG surgery and found a median CPB time of $94 \mathrm{~min}$. Similar to our findings, a longer $\mathrm{CPB}$ time predicted mortality [21].

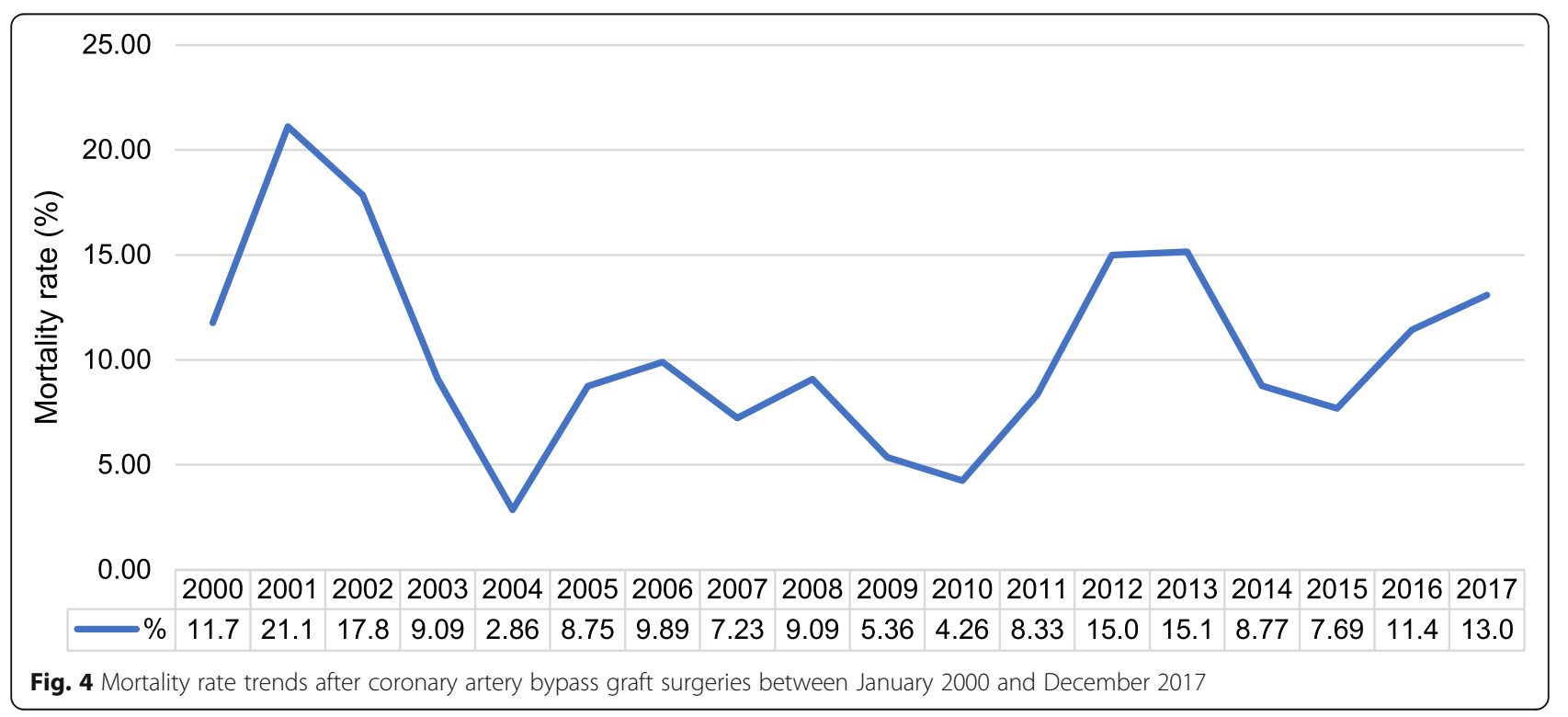


Table 2 Univariable and multivariable logistic regression analysis for predictors of in-hospital mortality

\begin{tabular}{|c|c|c|c|c|c|c|}
\hline & \multicolumn{3}{|c|}{ Linear regression } & \multicolumn{3}{|c|}{ Multivariable regression } \\
\hline & $\mathrm{OR}$ & $p$-value & $\mathrm{Cl}$ & $\mathrm{OR}$ & $p$-value & $\mathrm{Cl}$ \\
\hline Age & 1.04 & 0.000 & $1.02-1.06$ & & & \\
\hline Diabetes & 1.43 & 0.054 & $0.99-2.06$ & & & \\
\hline Dyslipidaemia & 0.43 & 0.000 & $0.30-0.62$ & & & \\
\hline Smoking & 0.55 & 0.001 & $0.38-0.80$ & & & \\
\hline NYHA class II & 2.32 & 0.000 & $1.46-3.68$ & & & \\
\hline NYHA class III & 3.00 & 0.000 & $1.69-5.30$ & & & \\
\hline NYHA class IV & 12.3 & 0.000 & $5.30-28.40$ & & & \\
\hline IABP (preop) & 2.80 & 0.000 & $1.95-4.01$ & & & \\
\hline IABP (postop) & 3.95 & 0.000 & $2.12-7.35$ & 1.42 & 0.002 & $0.52-2.31$ \\
\hline LVEF & 0.95 & 0.000 & $0.94-0.96$ & & & \\
\hline CPB time (min) & 1.01 & 0.000 & $1.01-1.02$ & 0.01 & 0.000 & $0.00-0.02$ \\
\hline EuroSCORE II & 1.21 & 0.001 & $1.16-1.27$ & 0.15 & 0.000 & $0.09-0.22$ \\
\hline
\end{tabular}

CPB Cardiopulmonary bypass; $C l$ Confidence interval; IABP Intra-aortic balloon pump; EuroSCORE European System for Cardiac Operative Risk Evaluation; LVEF Left ventricular ejection fraction; NYHA New York Heart Association; $O R$ Odds ratio

Risk prediction models have been developed as tools for patient risk stratification. Widely-used risk models in patients planned for cardiac surgery include the Society of Thoracic Surgeons (STS) and the EuroSCORE II [2224]. Although not externally validated in our population, the STS score and the EuroSCORE II are utilised in our hospital for risk assessment before CABG. The EuroSCORE II, revised in 2011, uses cardiac-specific and procedure-based variables to predict the patient's risk of mortality following cardiac surgery. Studies reporting actual and predicted mortality risk categorize the EuroSCORE II into low (score between 0.17 and 0.80), intermediate (score between 0.81 and 2.02), high (score between 2.03 and 4.11), and very high (scores between 4.14 and 47.60) categories [25]. In this study, the EuroSCORE II independently predicted mortality and was significantly higher in the group of patients that demised.

\section{Limitations}

Our study had several limitations. The study's retrospective nature limited our access to pertinent clinical data, as some records from the earlier years were incomplete. Only complications that occurred during the same admission as the CABG surgery were reviewed, and complications requiring readmission at a later stage were not analysed. Another limitation was a paucity of clinical information in the records of patients transferred from other hospitals within the referral network. In these instances, the clinical data was gathered from the referral letters and angiography reports.
We noted a variation in the mortality rate during the study period but could not account for this variation due to the study's retrospective nature. Furthermore, we identified a high rate of sternal wound infections but could not describe the organisms causing the infections in all patients with sepsis, nor define the treatment plan utilised. Despite these limitations, this retrospective review of perioperative complications in patients subjected to CABG surgery in a state-sector, tertiary academic hospital, adds more insights into locally relevant predictors of mortality and reports on the crude mortality rate over 17 years.

\section{Conclusions}

In our study, the perioperative mortality rate was $11.2 \%$, with most deaths attributed to cardiac complications. Excessive bleeding was the most frequent perioperative complication, reported in $18.2 \%$ of patients. Our mortality rate is significantly higher than the mortality rates reported in other developed and developing countries. To better understand the factors driving this high mortality rate, a prospective outcomes registry has been initiated and will inform on the contemporary mortality rate.

\section{Abbreviations \\ CABG: Coronary artery bypass graft; CAD: Coronary artery disease; CMJAH: Charlotte Maxeke Johannesburg academic hospital; COPD: Chronic obstructive pulmonary disease; CPB: Cardiopulmonary bypass; eGFR: Estimated glomerular filtration rate; EuroSCORE: European system for cardiac operative risk evaluation; ICU: Intensive care unit; LVEF: Left ventricular ejection fraction; NYHA: New York Heart Association; PVD: Peripheral vascular disease; STS: Society of thoracic surgeons; USA: United States of America}

\section{Acknowledgments}

The authors would like to thank Dr. Katharina Vanderdonck and the CMJAH Department of Cardiothoracic Surgery and Anaesthesiology for their assistance and support with obtaining patient records. We also acknowledge Dr. Marheb Badianyama, Dr. Vanessa Mogashoa, and Dr. Bavinash Pillay for assisting with collecting data.

\section{Authors' contributions}

Conception and design of the study: NT and DM. Data collection: SR and KV. Analysis and interpretation: NT, DM, KV, SR, PMC and SM. Drafting or critical review of the article: NT, DM, SR, KV, PMC and SM. The author(s) read and approved the final manuscript.

\section{Funding}

None

\section{Availability of data and materials}

The dataset used and analysed during the current study are available from the corresponding author on reasonable request.

\section{Ethics approval and consent to participate}

This study has been performed in accordance with the Declaration of Helsinki. Approval to conduct the study was obtained from the University of the Witwatersrand Human Research Ethics Committee (Protocol number M180701)

Consent for publication

Not applicable. 


\section{Competing interests}

The authors declare that they have no competing interests.

\section{Author details}

'Division of Cardiology, Department of Internal Medicine, Faculty of Health Sciences, School of Clinical Medicine, University of the Witwatersrand, Charlotte Maxeke Johannesburg Academic Hospital, 17 Jubilee Road, Parktown, Johannesburg 2193, South Africa. ${ }^{2}$ Division of Cardiothoracic Surgery, Department of Surgery, Faculty of Health Sciences, School of Clinical Medicine, University of the Witwatersrand and the Charlotte Maxeke Johannesburg Academic Hospital, Johannesburg, South Africa. ${ }^{3}$ Department of Anaesthesiology, Faculty of Health Sciences, School of Clinical Medicine, University of the Witwatersrand and the Charlotte Maxeke Johannesburg Academic Hospital, Johannesburg, South Africa.

Received: 17 July 2020 Accepted: 9 December 2020

Published online: 07 January 2021

\section{References}

1. Tsabedze N, McCutcheon K, Mkhwanazi L, Garda R, Vachiat A, Ramjee R, et al. Periprocedural myocardial infarction during percutaneous coronary intervention in an academic tertiary Centre in Johannesburg. Int J Cardiol. 2017;230:175-80.

2. Gupta R, Yusuf S. Challenges in management and prevention of ischemic heart disease in low socioeconomic status people in LLMICs. BMC Med. 2019;17(1):209.

3. Gupta R, Wood DA. Primary prevention of ischaemic heart disease: populations, individuals, and health professionals. Lancet. 2019;394(10199): 685-96.

4. Diodato M, Chedrawy EG. Coronary artery bypass graft surgery: the past, present, and future of myocardial revascularisation. Surg Res Pract. 2014; 2014:726158.

5. Onen CL. Epidemiology of ischaemic heart disease in sub-Saharan Africa. Cardiovasc J Afr. 2013;24(2):34-42.

6. European System for Cardiac Operative Risk Evaluation interactive calculator 2011. Available from: http://www.euroscore.org. Accessed 2 Nov 2020.

7. Nashef SA, Roques F, Sharples LD, Nilsson J, Smith C, Goldstone AR, et al. EuroSCORE II. Eur J Cardiothorac Surg. 2012;41(4):734-44 discussion 44-5.

8. Tie HT, Shi R, Zhou Q, Wang K, Zheng XQ, Wu QC. Annual case volume on mortality after coronary artery bypass grafting: a dose-response metaanalysis. Interact Cardiovasc Thorac Surg. 2019;29(4):568-75.

9. Yu PJ, Lin D, Catalano M, Cassiere H, Kohn N, Hartman A. Predictors of increased length of hospital stay in patients with severe cardiomyopathy undergoing coronary artery bypass grafting. J Cardiothorac Vasc Anesth. 2019;33(10):2703-8.

10. Vickneson K, Chan SP, Li Y, Bin Abdul Aziz MN, Luo HD, Kang GS, et al. Coronary artery bypass grafting in patients with low ejection fraction: what are the risk factors? J Cardiovasc Surg. 2019;60(3):396-405.

11. Movahed MR, Ramaraj R, Khoynezhad A, Hashemzadeh M, Hashemzadeh M. Declining in-hospital mortality in patients undergoing coronary bypass surgery in the United States irrespective of presence of type 2 diabetes or congestive heart failure. Clin Cardiol. 2012;35(5):297-300.

12. Goicolea Ruigomez FJ, Elola FJ, Durante-Lopez A, Fernandez Perez C, Bernal JL, Macaya C. Coronary artery bypass grafting in Spain. Influence of procedural volume on outcomes. Rev Esp Cardiol (Engl Ed). 2020;73(6): 488-94.

13. Swart MJ, Joubert G, van den Berg JA, van Zyl GJ. Tabula viva chirurgic: a living surgical document. Cardiovasc J Afr. 2016;27(3):170-6.

14. Peterson ED, Coombs LP, DeLong ER, Haan CK, Ferguson TB. Procedural volume as a marker of quality for CABG surgery. JAMA. 2004;291(2):195-201.

15. Birkmeyer JD, Siewers AE, Finlayson EV, Stukel TA, Lucas FL, Batista I, et al. Hospital volume and surgical mortality in the United States. N Engl J Med. 2002:346(15):1128-37.

16. Safaie N, Chaichi P, Habibzadeh A, Nasiri B. Postoperative outcomes in patients with chronic renal failure undergoing coronary artery bypass grafting in madani heart center: 2000-2010. J Cardiovasc Thorac Res. 2011; 3(2):53-6.

17. Mehaffey JH, Hawkins RB, Byler M, Charles EJ, Fonner C, Kron I, et al. Cost of individual complications following coronary artery bypass grafting. J Thorac Cardiovasc Surg. 2018;155(3):875-82.e1.
18. Kollef MH, Sharpless L, Vlasnik J, Pasque C, Murphy D, Fraser VJ. The impact of nosocomial infections on patient outcomes following cardiac surgery. Chest. 1997;112(3):666-75.

19. Howitt SH, Herring M, Malagon I, McCollum CN, Grant SW. Incidence and outcomes of sepsis after cardiac surgery as defined by the Sepsis-3 guidelines. Br J Anaesth. 2018;120(3):509-16.

20. Risnes I, Abdelnoor M, Almdahl SM, Svennevig JL. Mediastinitis after coronary artery bypass grafting risk factors and long-term survival. Ann Thorac Surg. 2010;89(5):1502-9.

21. Santos CAD, Oliveira MABd, Brandi AC, Botelho PHH, Brandi JdCM, Santos $M A D$, et al. Risk factors for mortality of patients undergoing coronary artery bypass graft surgery. Rev Bras Cir Cardiovasc. 2014;29(4):513-20.

22. Nashef SA, Roques F, Michel P, Gauducheau E, Lemeshow S, Salamon R. European system for cardiac operative risk evaluation (EuroSCORE). Eur J Cardiothorac Surg. 1999;16(1):9-13.

23. O'Brien SM, Feng L, He X, Xian Y, Jacobs JP, Badhwar V, et al. The Society of Thoracic Surgeons 2018 adult cardiac surgery risk models: part 2-statistical methods and results. Ann Thorac Surg. 2018;105(5):1419-28.

24. Shahian DM, Jacobs JP, Badhwar V, Kurlansky PA, Furnary AP, Cleveland JC Jr, et al. The Society of Thoracic Surgeons 2018 adult cardiac surgery risk models: part 1-background, design considerations, and model development. Ann Thorac Surg. 2018:105(5):1411-8.

25. Barili F, Pacini D, D'Ovidio M, Dang NC, Alamanni F, Di Bartolomeo R, et al. The impact of EuroSCORE II risk factors on prediction of long-term mortality. Ann Thorac Surg. 2016;102(4):1296-303.

\section{Publisher's Note}

Springer Nature remains neutral with regard to jurisdictional claims in published maps and institutional affiliations.

\section{Ready to submit your research? Choose BMC and benefit from:}

- fast, convenient online submission

- thorough peer review by experienced researchers in your field

- rapid publication on acceptance

- support for research data, including large and complex data types

- gold Open Access which fosters wider collaboration and increased citations

- maximum visibility for your research: over $100 \mathrm{M}$ website views per year

At BMC, research is always in progress.

Learn more biomedcentral.com/submissions 